\title{
FAILURE BEHAVIOUR OF A TUMBLE DRYER
}

\author{
S. Droessaert ${ }^{1}$, W. De Waele ${ }^{2}$, W. De Groote ${ }^{3}$, E. Delorge ${ }^{4}$ \\ ${ }^{1}$ Ghent University, Belgium \\ ${ }^{2}$ Ghent University, Laboratory Soete, Belgium \\ ${ }^{3}$ Spie Belgium, Piping and Mechanical \\ ${ }^{4}$ Sioen Fibres, Spinning Division, Belgium
}

\begin{abstract}
A tumble dryer is a rotating heated vessel used to fulfil a poly-condensation process of PETgranules. This step is very crucial in the entire production process of polymer fibres. System failure, causing production loss, cannot be afforded. Unfortunately, since a couple of years, the reactors suffer from severe cracking at weld details. To find the root cause(s) of this problem a detailed study of the vessel construction, the loads induced during the production process and the cracking has been performed. Hereby the influencing parameters and their importance could be determined. Based on this study it is put forward that fatigue, due to the exceptional translation of the granules in the vessel, is responsible for the cracking of the tumble dryer. Two main loading modes and corresponding crack locations could be determined: a cyclic changing torque causes the cracks on the outside of the vessel while the dynamic play of the moving granules around the heating elements is responsible for the cracks at the inside the tumble dryer. The root cause of the cracking problem has been determined but the actual mechanism causing the cracks, still needs to be quantified.
\end{abstract}

Keywords Inspection, welding, construction, fatigue, fracture

\section{INTRODUCTION [1]}

A tumble dryer (Figure 1) is a patented device which is used in the polymer fibre industry. Polymer fibres are produced from PET-chips. However, before this material can be used for the production of fibres, the PET-chips have to undergo a heat treatment which is called a post-condensation process. This is the process that is taking place inside the tumble dryer. During this treatment all impurities are removed and the viscosity of the chips is adapted to meet the requirements of the subsequent process steps.

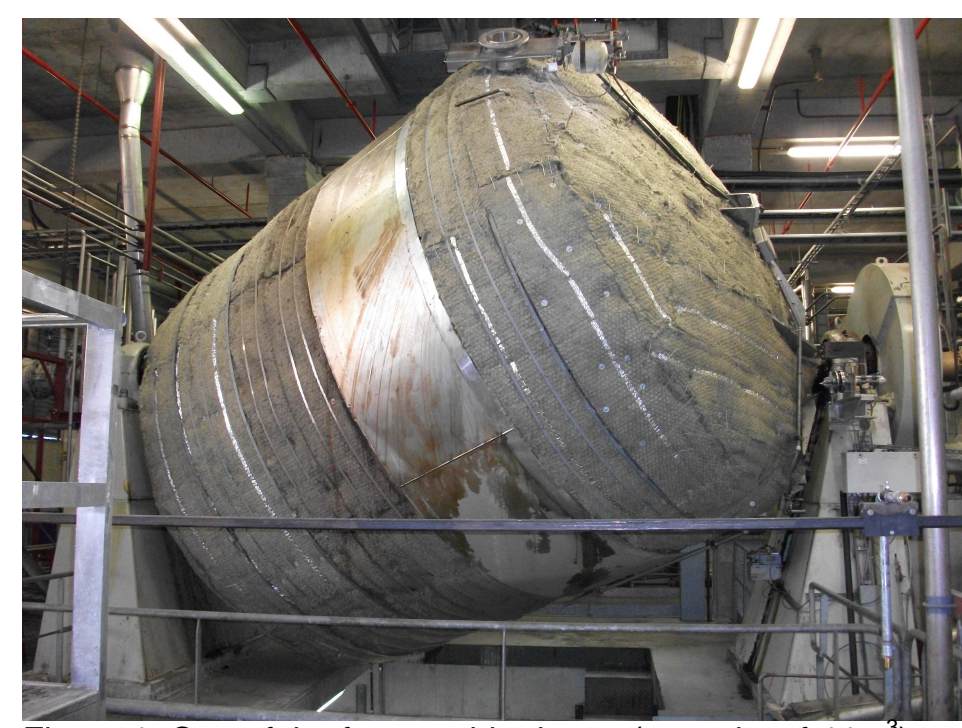

Figure 1: One of the four tumble dryers (capacity of $44 \mathrm{~m}^{3}$ ) at the Spinning Division of Sioen Fibres.

Four tumble dryers of this type are continuously in operation at the Spinning Division of Sioen Fibres (Moeskroen, Belgium) to meet the production demand. In the year 2000 the first two smaller units, with a capacity of $36 \mathrm{~m}^{3}$, have been installed. In 2003 there was a production expansion with 2 bigger units each having a capacity of $44 \mathrm{~m}^{3}$. Initially the tumble dryers operated well. As of 2007 the first problems in one of the vessels emerged. At random locations cracks were found in different crucial welds, both at the inside and outside of the vessel. These cracks were systematically resolved but the problem continuously shifted to other sections of the vessel. Constructional adaptation by the supplier did not solve the problems, on the contrary they even worsened the situation. Eventually they even had to undo some of the adaptations. So far no satisfactory solution for the cracking problem has been found. The troubles with the tumble dryers already resulted in a lot of (financial) production losses and a lack of reliability of these important production tools.

The goal of this study is to define the root cause of the observed weld cracks. For this reason a detailed overview of the occurring cracks has been made. Hereby it is important to the crack types, the locations of 
the cracks and their time of occurrence. Furthermore a detailed study of the reactor and of the process has been performed in order to define all influencing parameters. Based on these results, the intervening loads (mechanical, thermal, etc.) have been determined. In the near future, a detailed and critical study of the design, material choices and dimensions has to be performed. Both the global design and implementation details will be considered. Based on the final results of this study we will eventually try to provide a technical solution to the problem.

\section{SHORT OVERVIEW OF OBSERVED CRACKS}

In collaboration with the contractor SPIE, a detailed study has been performed to map the location and the frequency of crack occurrence. A first conclusion is that cracks appear both at the inside and the outside surface of the vessel. The cracks on the outside are situated at the connection of the vessel supports with the axis of the vessel and the connection with the outer shell. All cracks appear at discontinuities of the weld details and thus in a region with high stress concentration. Most of these cracks occur at the transmission side of the tumble dryer. In fact all supports at this side already needed a repair. Failures at the vacuum side only resulted in two repairs at the tip of the shortest supports. Cracks leading to failure of the heating paddles have been observed at almost every weld detail of this element. Figure 2 gives an impression of some important failures.

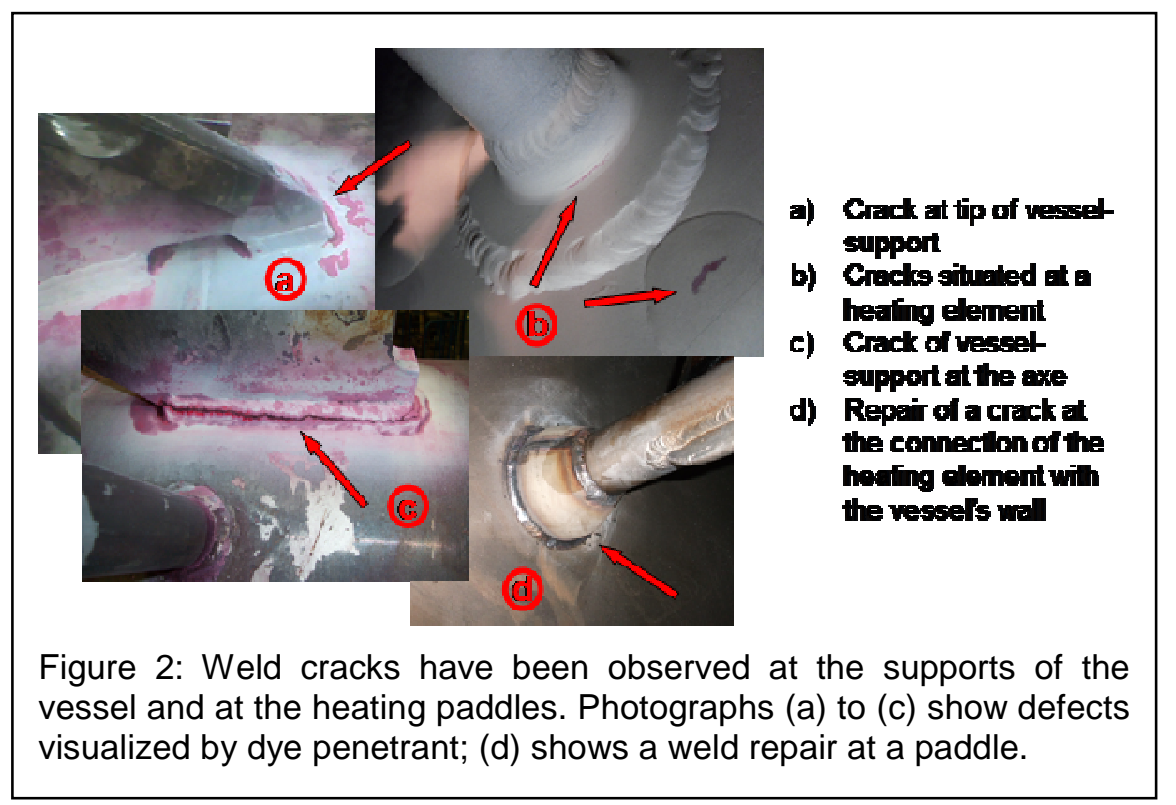

\section{STUDY OF THE TUMBLE DRYER}

\subsection{The production process}

Figure 3 represents a schematical overview of this production step. The applied post-condensation process entirely takes place in the tumble dryer which is a double shelled vessel (central part of the figure). Two chambers can be considered: one inner vacuum chamber filled with the PET-chips (in blue) and a surrounding chamber filled with circulating heated oil (in orange).

For heating the vessel's contents, oil with a temperature of maximum $250^{\circ} \mathrm{C}$, is pumped into the oilchamber at a pressure of $2 \mathrm{bar}$. To realise a homogeneous heat distribution throughout the entire vessel an internal heating system consisting of paddles and connected to the oil chamber is installed The maximum heating and cooling speed is limited to $2 \mathrm{~K} / \mathrm{min}$.

In the first step, the reactor is heated until the vessel temperature reaches $120^{\circ} \mathrm{C}$. Then the vessel is filled up to $75 \%$ of its capacity $\left(V_{\text {load,max }}=33,7 \mathrm{~m}^{3}\right)$ with PET-chips (having a cylindrical shape). The ingoing viscosity Visc. in of the chips is approximately $0,64 \mathrm{dl} / \mathrm{g}$. The pouring weight is about $0,8 \mathrm{~kg} / \mathrm{l}$ which means that $1 \mathrm{~g}$ counts about 50 chips. The melting temperature $T_{s}$ of the chips is over $258^{\circ} \mathrm{C}$. In the next step the reactor is rotated with a speed of $0,561 \mathrm{rpm}$. The vessel makes a tumble movement as it rotates around a diagonal of the cylinder. This tumbling movement results in an easeful mixing and homogeneous temperature distribution of the vessel's contents. While rotating the reactor, the temperature is increased up to $170^{\circ} \mathrm{C}$. 


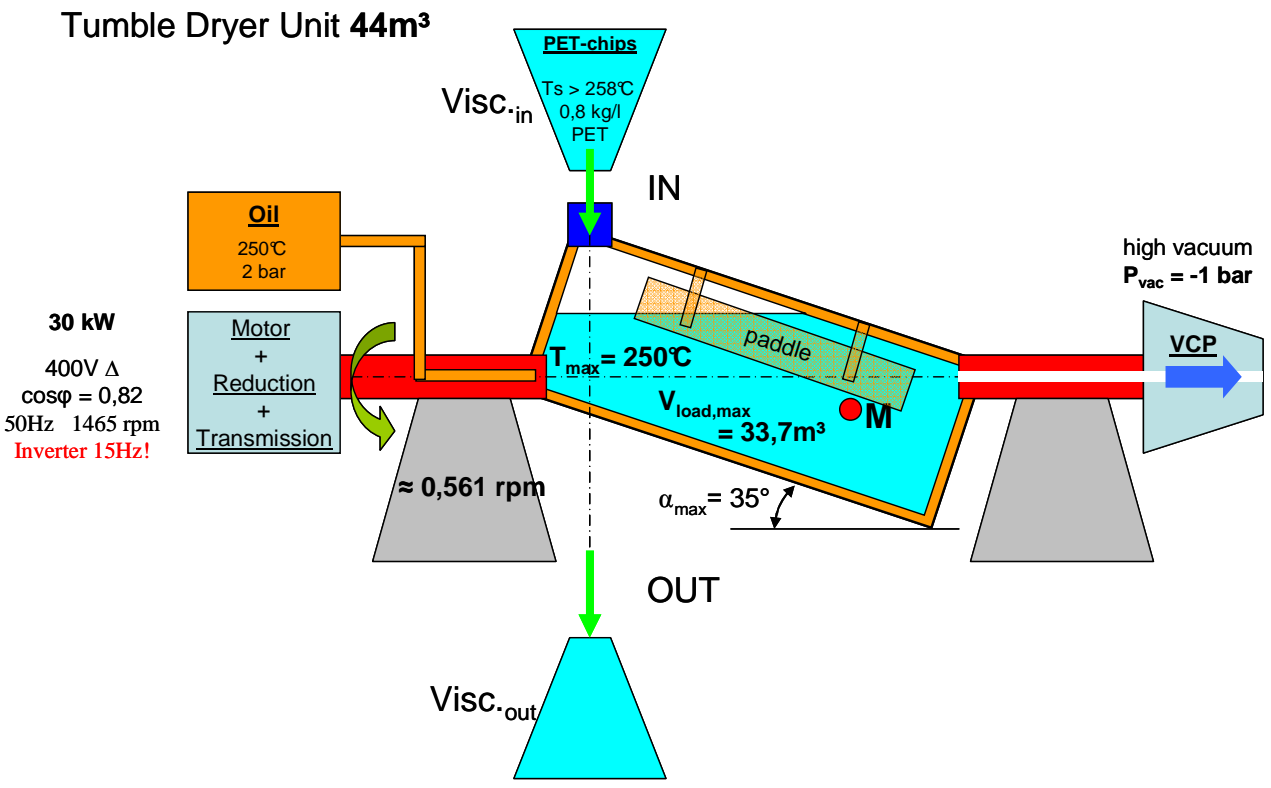

Figure 3 : Schematic illustration of the process characteristics

During this stage of the process the vacuum pump is also activated. Thereby the pressure drops to approximately -1 bar. When a homogenous temperature is reached, the reactor is heated up to the final temperature $225^{\circ} \mathrm{C}$. Viscosity change starts to take place when a temperature of $185^{\circ} \mathrm{C}$ has been reached. The further processing time is a function of the required viscosity. For the treatment of a standard batch a process time of approximately 40 hours has to be taken into account.

\subsection{The reactor construction [2][3][6]}

Due to the lack of detailed drawings a 3D model was sketched based on an assembly drawing. This model will help to understand the behaviour of the tumble dryer (Figure 4). The working part of the installation is the vessel. This vessel is supported by two axes: one axis driven by a triplex chain and one non-driven axis situated at the vacuum side of the tumble dryer. These axes are carried by two self adjusting cylindrical roller bearings which are installed on the substructure. Six external supporting fins, on both sides of the vessel, are used to connect the vessel with the axes through weld joints. To reduce the thermal losses, the reactor is covered with a layer of isolating material (Figure 1).. Additional supports are present on the inside of the vessel. However, these fixtures are not visible as they are covered with a plate (not shown on the figure). For this reason it is at this moment not certain if these supports are crack free.

Principally the reactor is an assembly of two vessels that have been put together (Figure 5). The inner vessel is completely made of stainless steel. To create a smooth surface on the inside of the inner vessel, a technique with distance tubes has been used to fix both vessels together (Figure 7). Thus all welding operations could be done from the outside of the inner vessel and only a limited amount of welds are visible on the inside. For the outer vessel two different types of steel are used: stainless steel for the cylindrical part and carbon steel for the bottom of the vessel.

The vessels are designed according tot the AD Merkblätter. As is prescribed, the bottom of the vessel is designed according to the German standard DIN 28011 (AD 2000-Merkblatt, List of all standard, quoted in the $A D 2000$ body of regulations). This implies that the vessel consists of a cylindrical part completed by a torispherical head at both sides. The most critical point of such a vessel can be situated at the transition from the cylinder to the end cap. The tension stress in this region increases with a decreasing ratio of the transition radius to the vessel diameter, and with an increasing ratio of the global end bottom radius to the vessel diameter.

The heating system consists of 16 paddles evenly divided along the vessel's circumference. Three hollow tubes connect the heating element to the vessel wall and allow heated oil to flow into the paddles. Each paddle is also connected with every neighbouring element to increase the system's stiffness. The heating element (Figure 8) is an assembly of two plates which are welded together at their sides. To avoid the plates of the heating element to deform due to the internal oil pressure, the plates are connected with small rods, evenly distributed over the heating element. 
Throughout the structure, elements made of different materials (carbon steels, stainless steels) have to be welded together. To avoid cracks in such composite welds, a suitable filler material can be selected using for example the Schaeffler diagram, or the WRC-diagram (which is an improved version).

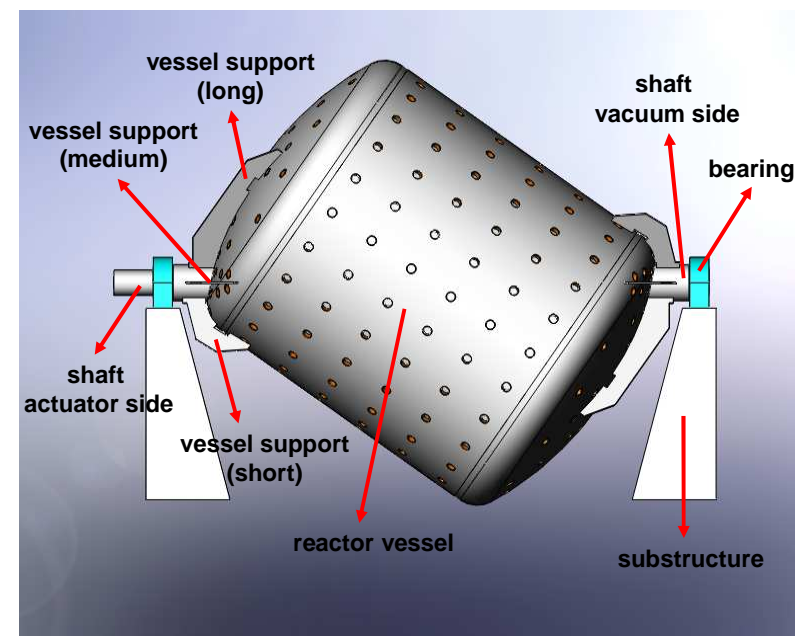

Figure 4: 3D model of the tumble dryer

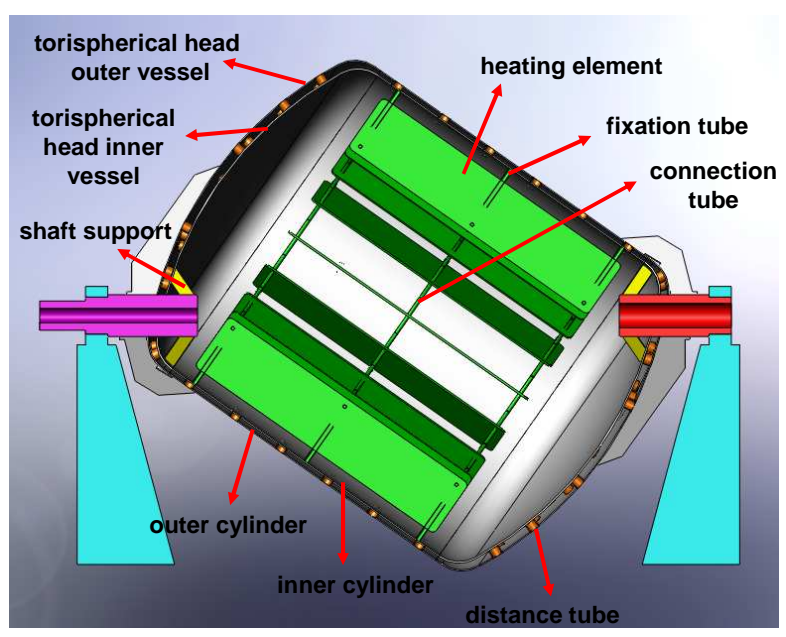

Figure 5: Cross section view of the tumble dryer

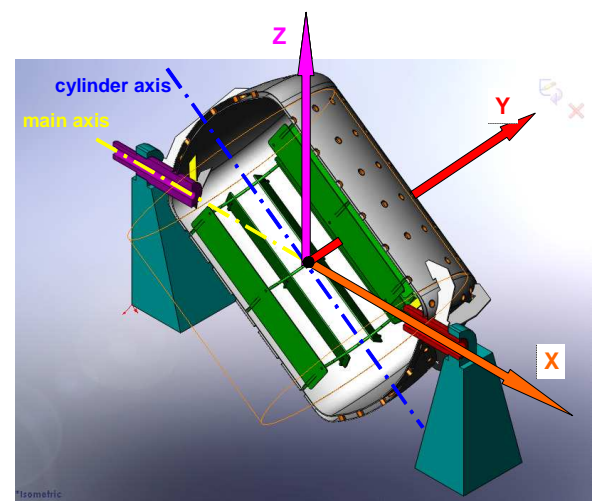

Figure 6: Orthogonal trihedron

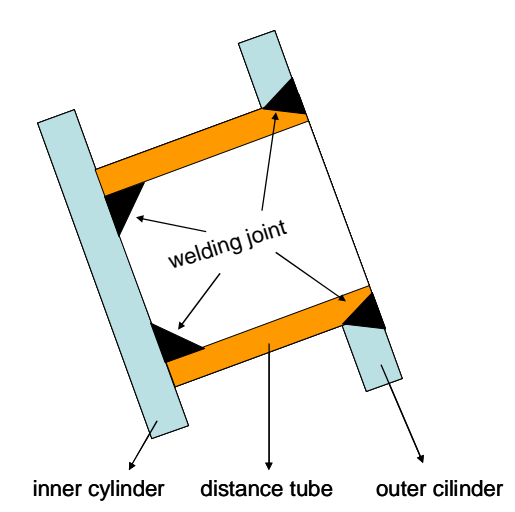

Figure 7: Detail of the distance tube connection

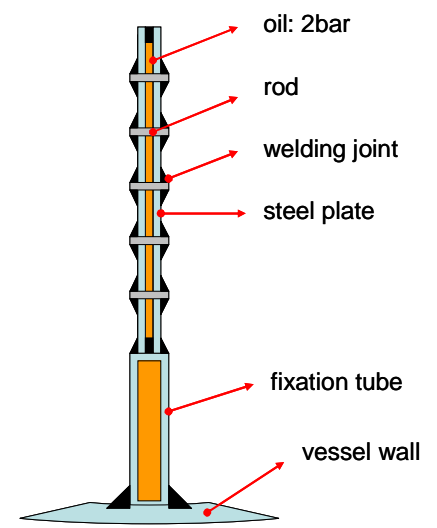

Figure 8: Cross section view of a heating element

\subsection{Motion study}

For describing the reactor's movement, an orthogonal trihedron was introduced as shown in Figure 6 . Its origin coincides with the mid-point of the centreline through the shaft of the tumble dryer. Using the $X Y Z$ axes, the centreline through the shaft and the vessel's axis of axial symmetry, a simplified representation can be used to render the instantaneous position of the reactor. Projecting the vessel's axis of axial symmetry onto the $\mathrm{XY}$ - and $\mathrm{XZ}$-plane, two reference angles can be defined: the tilt angle $\alpha$ and the spiral angle $\beta$ (Figure 9). The construction of the tumble dryer is choosen in such a way that the centreline through the shaft coincides with a diagonal of the cylinder. The angle between this diagonal and the vessel's axis of axial symmetry is $35^{\circ}$. This implie s that the tilt angle and spiral angle must meet to the following expressions:

$$
\begin{aligned}
& -35^{\circ} \leq \alpha, \beta \leq 35^{\circ} \\
& |\alpha|+|\beta|=35^{\circ}
\end{aligned}
$$

It can be concluded that the introduced system makes it possible to describe unequivocally the vessel's position at any time. Figure 10 shows how the position of the tumble dryer changes during its rotation. 


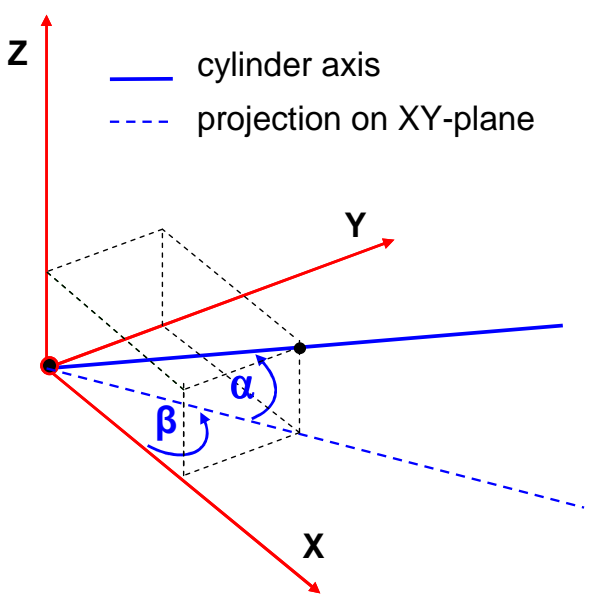

Figure 9: Definition of tilt angle $(\alpha)$ and spiral angle $(\beta)$
Left turning

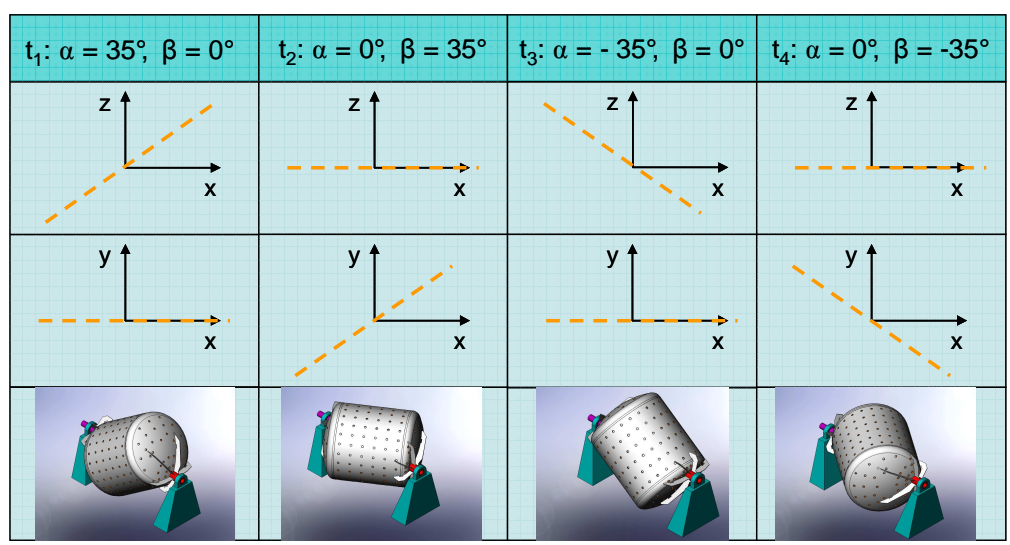

Figure 10: Evolution of the vessel's position

\subsection{Analysis of the service loads [4][5][7]}

Based on the study of the process shown in Figure 2, five influencing load factors could be distinguished:
a. Net weight of the construction
b. Vacuum pressure inside the reactor
c. Oil pressure between the inner and outer shells
d. Temperature gradients
e. Weight and movement of PET granules

To obtain an improved insight in the mechanical behaviour of the vessel (i.e. its deformations due to the above listed loadings), some simplified preliminary calculations have been made. Therefore the tumble dryer has modelled as a cylindrical tube with a double wall, having the same dimensions as the real vessel.

First the static deflection of the tumble dryer due to the net weight of the construction has been estimated. The net weight can be modelled as an evenly distributed load engaging a beam clamped at both ends beam. Hereby it is assumed that the vessel has a much higher stiffness than the axes. A deflection of $36 \mu \mathrm{m}$ at the connection between the driven axis and the vessel was calculated. Due to the very small relative deflection, the influence of the net weight of the vessel can be neglected.

The study of the effect of the oil pressure and the internal vacuum can be treated together. We first consider the inner cylinder and then the outer one. The influence of the distance tubes has been modelled by replacing them with an uniformly distributed pressure $P_{R}$. This pressure was calculated based on the assumption that inner and outer cylinder have the same radial displacement (expression of compatibility). $P_{R}$ can be found as:

$$
P_{R}=\frac{R_{1}^{2} h_{2} \cdot(P+O)+R_{2}^{2} h_{1} P}{R_{1}^{2} h_{2}+R_{2}^{2} h_{1}}=2,514 b a r
$$

From this result we can conclude that the inner and outer shells of the vessel clearly interact, an effect that should not be ignored in further calculations. For the radial displacement of the inner shell we find:

$$
u_{n}=\frac{\left(P_{R}-P-O\right) \cdot R_{1}^{2}}{2 h_{1}} \cdot \frac{2-v}{E}=-0,0672 \mathrm{~mm}
$$

Due to the internal vacuum and the oil pressure between the shells, the vessel will shrink with a very small radial displacement of about $67,2 \mu \mathrm{m}$.

The temperature of the vessels changes very slowly with a maximum speed of $2 \mathrm{~K} / \mathrm{min}$. If the reactor is used in a continuous way throughout the year, there are about 219 heating and cooling cycles a year. This means that we can consider the temperature as a static influence. To make a prediction of the expansion of the vessel due to the temperature rise $\left(20^{\circ} \mathrm{C}=>250^{\circ} \mathrm{C}\right)$, a linear thermal expansion coefficient $\alpha$ equal to $17.10^{-6} / \mathrm{K}$ has been used. The vessel will increase in length with $150 \mathrm{~mm}$ while the diameter increases with 
about $147 \mathrm{~mm}$. At first sight this looks quite large, but it is to be compared with the huge dimensions of the vessel $(4,910 \mathrm{~m}$ long and $3,800 \mathrm{~m}$ in diameter). Though we have to pay attention as the linear expansion coefficients of the inner and outer torispherical head have a different value (respectively 17 and 13,6 10 $6 / K)$. Due to the different thermal expansion coefficients of the two shells, thermally induced stresses can occur. This will be studied in future work.

To determine the influence of the weight and movement of the PET granules, we need another approach. Studying the process on figure 3 reveals that the position of the chips' centre of mass is not displaced symmetrically during the rotational movement. Because the vessel is not filled completely, the centre of mass $M$ will follow a 3 dimensional curve through the vessel. To study this phenomenon we need to know the location of $M$ for every position of the vessel (determined by alpha and beta). The results of these calculations are presented in Figure 11.

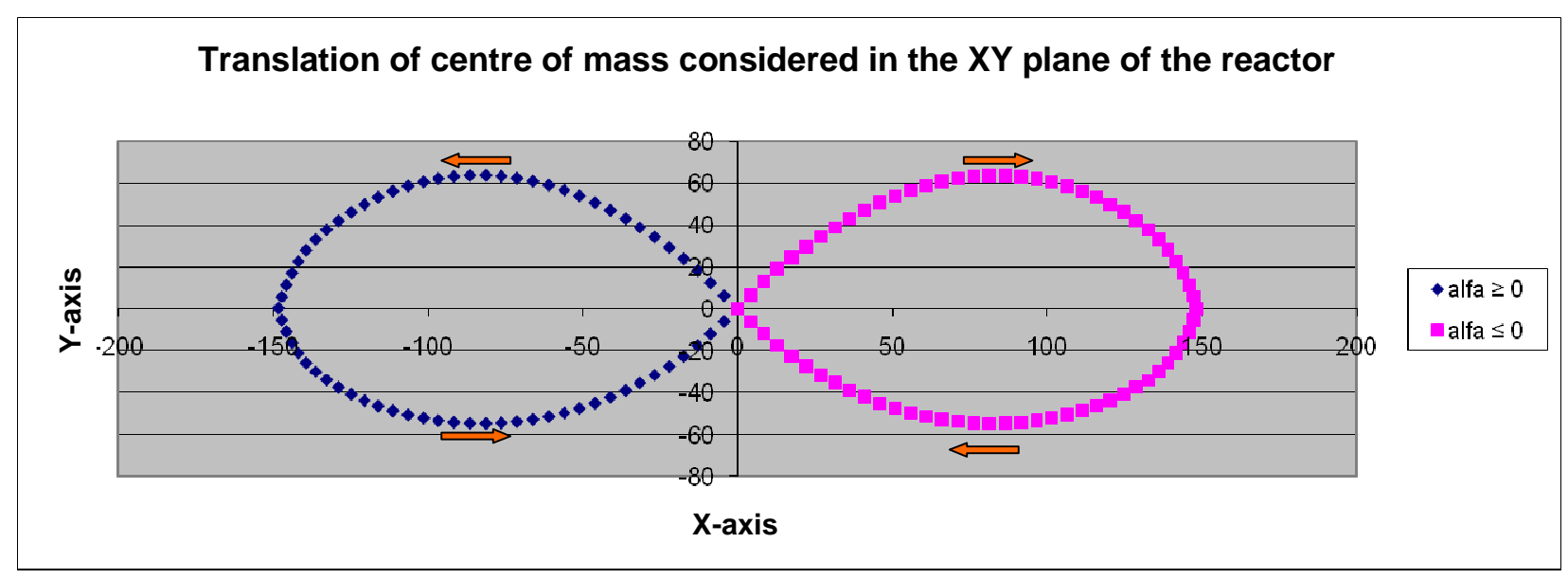

Figure 11: Translation of centre of mass considered in the $\mathrm{XY}$ plane of the reactor

It is clear that during one rotational movement the centre of mass describes a "horizontal figure 8" in the $\mathrm{XY}$-plane. This implies that during one rotation the torque-rate changes 4 times. If the Y-coordinate of $M$ has a positive value, the torque is reinforced while a negative value for $Y_{M}$ results in a drop of the torque. The periodical change of torque in time can be expressed as:

$$
T=m_{\text {chips }} \cdot 9,81 \cdot C \cdot Y_{\max } \cdot \sin \left(\frac{4 \pi \cdot 0,561}{60} t\right)=41,655 \cdot \sin \left(\frac{4 \pi \cdot 0,561}{60} t\right) \quad[\mathrm{kNm}]
$$

To verify these results, an electrical power measurement of the driving motor has been performed (Figure 12). The calculated profile is adapted with a factor $\mathrm{C}=0,25$ to match with the measurements. This correction was necessary because the flow behaviour of water differs from the behaviour of solid particles due to: friction, bulk density, dilatancy, shape of the particles etc. So we can conclude that the mass displacement of the granules generates a dynamic change of the driving torque. This effect is expected to have a serious impact on the tumble dryers' fatigue endurance live.

The displacement of $M$ in the X-direction will also have a non-negligible and dynamic effect on the amplitude of the tangential force on the axis. This means that the periodical change of amplitude of the tangential power will also affect the system's fatigue endurance live. 


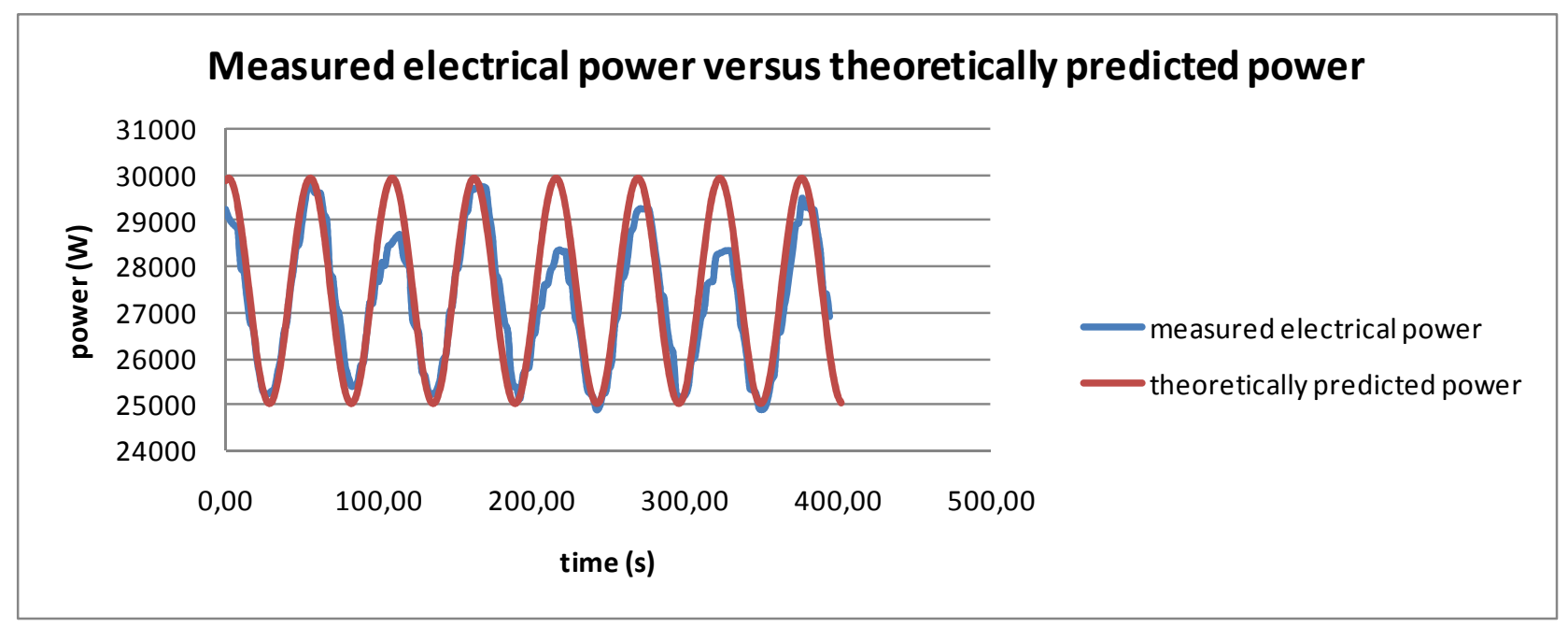

Figure 12: Measured electrical power versus theoretically predicted power

\subsection{Further research}

To determine the effective torque on the driven axis of the tumble dryer, strain gauge measurements will be performed. This way, one can exclude the influence on torque amplitude allocated to transmission losses. Further, the global stresses and deformations of the vessel and the hotspots of the system (locations with high tensile stresses) will be localized using a FEM-analysis. With these results, fatigue life calculations can be done. Also the dynamic play of the granules around the heating elements will be investigated. The results of this study will be checked to see if they meet the requirements of the applied standards and codes. Further research activities will be performed to find out how the fatigue live of this dynamic system can be improved. Based on these findings technical solutions will be presented.

\section{CONCLUSIONS}

It can already be established that the dynamic behaviour of the vessel's contents play a decisive role in the (fatigue) cracking of the tumble dryer. Based on the locations and kind of cracks, two critical loading conditions can be determined. The first one is a dynamic torque due to a centre of mass displacement of the granules inside the vessel. This phenomenon mainly causes the cracks observed at the supports on the outside of the vessel. A second critical loading mode can be assigned to the dynamic play of the granules around the heating elements of the vessel and is thereby responsible for the cracks in the welds of the paddles. Summarizing, the weight and movement of the granules can be considered as the main reasons for the vessel failures while all other influencing parameters have a minor or negligible effect.

\section{NOMENCLATURE}

$\begin{array}{lll}T & \text { torque } & \mathrm{Nm} \\ P & \text { (oil-) pressure } & \mathrm{Pa} \\ h & \text { wall thickness } & \mathrm{m} \\ E & \text { Young's modulus } & \mathrm{N} / \mathrm{m}^{2} \\ R & \text { radius cylindrical vessel } & \mathrm{m} \\ V & \text { Poisson-ratio } & - \\ t & \text { time } & \mathrm{sec} . \\ O & \text { vacuum pressure } & \mathrm{Pa} \\ P_{R} & \text { Reaction Pressure } & \mathrm{Pa} \\ u_{n} & \text { Normal Displacement } & \mathrm{m}\end{array}$

\section{REFERENCES}

[1] http://www.ohl-eng.com/en/process/ssp.html 18/09/2010

[2] G. den Ouden, M. Hermans, Welding Technology, VSSD Delft, p152, 2009

[3] D. MUHS, H. WITTEL, M. BECKER, D. JANNASCH, J. VOSSIEK, Roloff/Matek, $4^{\text {de }}$ druk 2007, p581

[4] P. Verleysen, Mechanica van werktuigkundige constructies, Ugent, Toegepaste materiaalwetenschappen, p6.18, 2008-2009.

[5] J.Pollefliet, Elektrische Vermogenscontrole, Vol.2 Elektronische motorcontrole, $6^{\text {de }}$ druk $2^{\text {de }}$ oplage, Academia Press, Gent, 2007

[6] AD 2000 code, technical rules for pressure vessels, July 2003

[7] Richard. G. Holdich, Fundamentals of particle technology, Department of chemical engineering, Loughborough university, U.K., 2002, p363 